ever there was one. But it was steadfast, if not without turbulence. That is perhaps the most unexpected facet of a life that supplies other unimagined nuggets Dirac's lifelong love of Mickey Mouse cartoons, for example, or his touching latter-day reverence for the American starlet Cher.

So what made Dirac the man he was? Attempting to answer such questions risks the descent into psychobabble, but Farmelo makes a worthy attempt at offering a diagnosis. It is clear that Dirac harboured a lifelong resentment of his father, whose domineering personality he blamed for an unhappy childhood and for the suicide of his elder brother, Felix, in 1925 - an event that evidently affected him more deeply than his own words could ever express.

But Farmelo sees the answer to Dirac's oddities more in nature than in nurture. He lays out the evidence: Dirac's uncanny ability to see the world in entirely abstract forms; his total absence of guile "childlike, but never childish", as one Cambridge contemporary described it; his seeming inability to express his emotions or empathize with others. The conclusion he reaches positively screams itself to the modern reader, whatever its scientific worth: Paul Dirac was autistic.

Whether that is a particularly revealing conclusion, or indeed whether another 'outlier' thus diagnosed adds significantly to arguments about the nature of genius, is perhaps debatable. Farmelo is wise to relegate the issue to a postscript. Ultimately, the answer is neither here nor there in a book that is a rewarding account of an enigmatic man and an intriguing era of physics.

\section{REVIEWED BY RICHARD WEBB}

Richard Webb is a features editor for New Scientist.

\title{
Lucky for some
}

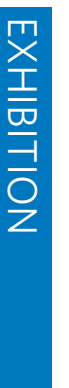

\author{
New York's Museum of \\ Modern Art (MoMA) is \\ celebrating its acquisition of \\ 13 recent compositions by \\ Jasper Johns, with a 'focus' \\ exhibition that draws on its \\ extensive collection of the \\ US artist's work. \\ The newly acquired \\ prints, created in 2001 and \\ all untitled, share a
}

mathematical theme. Each features the catenary - the shape formed by a flexible chain hanging under gravity between its two supported ends, and rendered mathematically in terms of the hyperbolic cosine. Despite its familiarity throughout centuries of architecture, the recognition of the catenary form dates only to the second half of the seventeenth century: as St Paul's cathedral was rebuilt from the ashes of the Great Fire of London, Robert Hooke declared it the optimal shape of an arch (although, rather unhelpfully, he only published an encrypted solution in his lifetime). The word 'catenary' - rather than the original 'catenaria', from the Latin catena for 'chain' - seems to have first been used in a 1788 letter from Thomas Jefferson to Thomas Paine.

Johns is known for his use of images. In the work pictured here, one of the untitled 13, the catenary is partnered with impressions of an old-fashioned family portrait, a spiral galaxy, and the image that features most famously in Johns' repertoire, the flag. His iconic work of 1954-55, Flag, is also held by MoMA. This seemingly straightforward rendering of the star-spangled banner - although with 48 stars, as it predates the admission of Alaska and Hawaii to the Union - belies

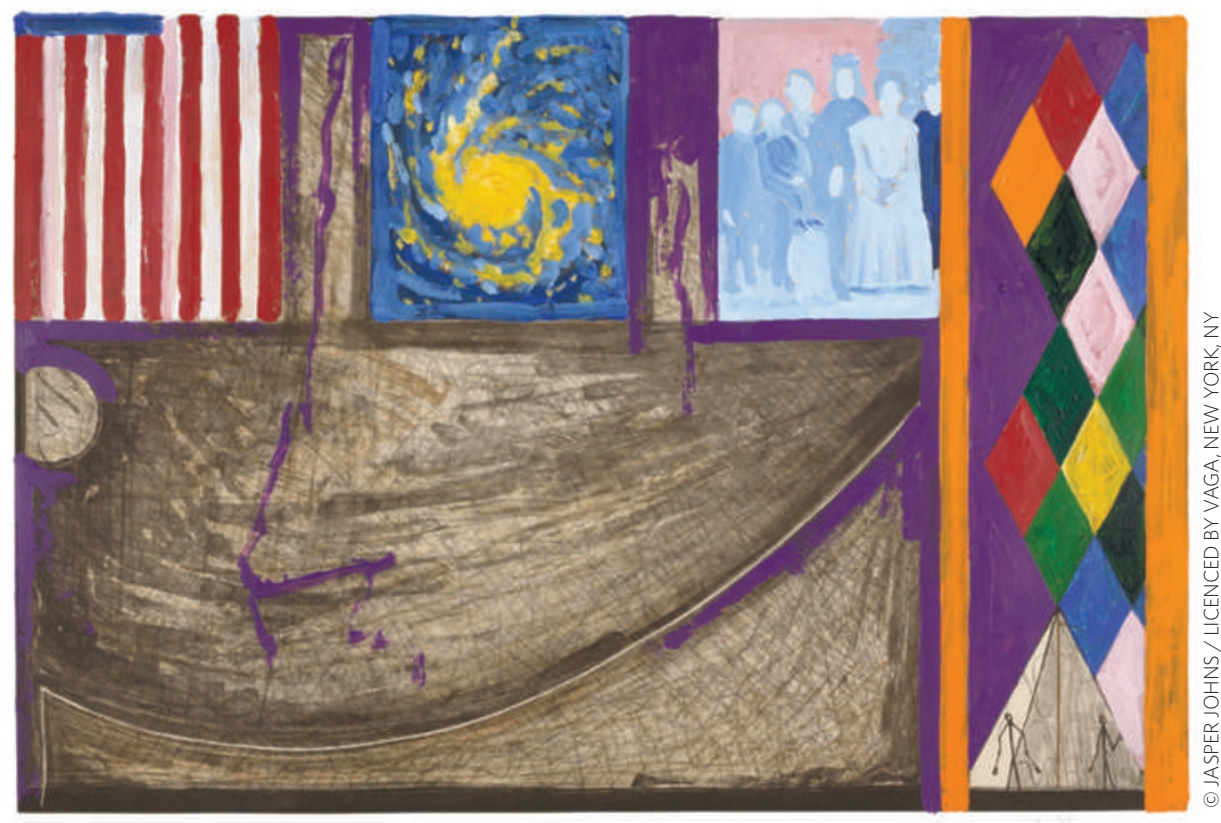

the complexity of its creation, built up in encaustic (a wax-based paint) layered over other materials such as newsprint on fabric mounted on plywood. Untitled (pictured) was created in acrylic over aquatint and etching.

Alongside the flags, numbers have also been a prevalent motif in Johns' work. Among the 85 prints, drawings and painting from MoMA's collection that form the current exhibition are two variations of a portfolio entitled 0-9. Dating from 1963 , one is printed in a range of colours on white paper, the other in grey ink on brown; both sets were made from a single lithographic stone, Johns having reworked its surface after the printing of each numeral.
Through his use of popular iconography, Johns is often recognized - alongside Robert Rauschenberg and others such as French artist Yves Klein - as a 'neo-Dadaist', in reference to the earlier Dada movement that included Marcel Duchamp, Francis Picabia and Man Ray. The MoMA display of its new prints, in the wider context provided by the museum's collection of Johns' work, provides, according to exhibition curator Deborah Wye, "a focus that demonstrates his investigatory process especially well."

Focus: Jasper Johns is at the Museum of Modern Art, 11 West 53 Street, New York until 16 February 2009.

\section{ALISON WRIGHT}

